\title{
AOR
}

Selected Papers of \#AolR2021:

The 22nd Annual Conference of the Association of Internet Researchers Virtual Event / 13-16 Oct 2021

\section{'WHEN YOU REALISE YOUR DAD IS CRISTIANO RONALDO': CELEBRITY SHARENTING AND CHILDREN'S DIGITAL IDENTITY}

Ana Jorge

CICANT/Lusófona University

Lidia Marôpo

Polytechnic Institute of Setúbal/CICS.NOVA

Filipa Neto

FCSH-UNL

\section{Introduction}

Sharenting - the practice of the sharing of parenthood experiences through social media - is now frequent across cultures. While it refers to sharing any type of information about children and parenting, we interrogate sharenting in its eminent visual dimension, and in relation to celebrity parents.

This paper draws on Children, Youth and Media; on Celebrity Studies; and on Digital Culture and Digital Methods. The goal is to understand the digital identity of a child of a global celebrity through their presentation on social media; and to retrieve visual formats of the child's representation and undergo a qualitative analysis. It focuses on the representation of Cristiano Ronaldo's children, especially his oldest son, through his social media, Instagram in particular, and in the highly fluid visual digital culture.

\section{Theoretical framework}

The growing body of research about sharenting has looked at ordinary users (Livingstone \& Blum-Ross, 2017; Siibak \& Tracks, 2019; Ouvrein \& Verswijvel, 2019) or semi-professional bloggers (Jorge et al., 2021; Mäkinen, 2020), and especially associated with mothers. This scholarship has debated the tension between the right of parents to share their parenting experiences and their children's right to privacy (Steinberg, 2017) as well as children's right to participation. Emergent research has focused on the tensions between different agents around the children besides the parents: teachers (Cino \& Vandini, 2020a), mothers-in-law (Cino \& Vandini, 2020b), or 
grandparents. Some parents are 'anti-sharenting' or refraining from engaging in social media about their children (Autenrieth, 2018).

When performed by celebrities, sharenting works to give the audiences elements of privacy that used to be hidden or gatekept by the media, show ordinariness in the lives of celebrities and ascribe them a 'moral authenticity' (Mortensen \& Jerslev, 2014, p. 628). Sports celebrities, like Ronaldo, have special moral expectations (Whannel, 2005) and are associated with increased authenticity, as their merit is seen as less fabricated than other celebrities.

Digital environment is increasingly characterized by platformisation (Helmond, 2015). The integration of web applications, including social media, with each other and the wider web is motivated by technical and economic factors, as the model feeds on the flows of data and information within and across those applications. In this environment, visual elements are central (Highfield \& Leaver, 2016; Highfield, 2018), as a result of commercial visual repositories and participatory digital culture - encompassing from memes to stickers, gifs, or filters. Research on visual cultures, "a more unwieldy category for comparative work" (Pearce et al., 2020, p. 165), has been less preferred than linguistic search.

\section{Methods and material}

This paper focuses on the representation of Cristiano Ronaldo's children ${ }^{1}$, particularly Cristiano Junior. In the first phase, we analyzed Instagram accounts by @cristiano (the most-followed individual on Instagram since 2018, with over 275 million followers at the end of 2020), his partner @georginagio (24.1 million followers in April 2021), and his mother @doloresaveiroofficial (2.2 million followers), between May 2018 and May 2020).

In the second level of analysis, we searched for Cristiano Junior across different digital spaces and cultures - image search engines (Google, Yahoo and Bing), social media platforms (Reddit, Tumblr, Instagram, Facebook, Twitter), sites (BuzzFeed), repositories (Giphy, Imgur, Pinterest) - using hashtags and text with a blank browser account. To counterbalance the linguistic bias of this type of search, we used reverse image search (Google Lens and Reverse Vision, TinEye) for the identified memes. We then thematically grouped the images to capture the association between formats, platforms and the child's identity resulting thereof.

\section{Findings}

On the Instagram's family accounts we found that: Ronaldo's children were represented mostly in domestic moments, in non-staged aesthetics and selfies, often playing, sometimes amidst conspicuous luxury; Junior appears with the father and stepmother in their posts about business/social events and commercial endeavors; he is presented as

\footnotetext{
${ }^{1}$ Cristiano is the father of four children: Cristiano Junior, born in 2010 from a publicly unknown mother; Eva e Mateo, born in June 2017 through surrogacy; and Alana Martina, born in November 2017 from Georgina Gio, his partner. He is Portuguese and has played football in the UK, Spain, and now Italy.
} 
a 'natural successor' to Ronaldo's talent for football, whereas girls are more associated with princesses roleplaying; and his grandmother shows the boy amidst his siblings and cousins, in school moments or accompanying her in her daily life.

We detected that these representations of Junior are specially appropriated by the participatory culture into memes that mock the father's narcissism; or the fact that the child doesn't know how to pose for selfies. The series of memes '-Dad, I'm hungry/ -l'm so handsome' (in Portuguese) generated in Brazil in 2018 illustrates this.

Cristiano's children's digital identity and Junior's, in particular, is populated with images as shared by parents and wider family, as well as constructed through participatory culture. A critical lens and an archaeological approach prove to be fruitful to unpack the tensions of this wide visibility and the meanings it creates for the (digital) identity of the child.

\section{References}

Autenrieth, U. (2018). Family photography in a networked age: Anti-sharenting as a reaction to risk assessment and behaviour adaption. In G. Mascheroni, C. Ponte, \& A. Jorge (Eds.), Digital Parenting: The Challenges for Families in the Digital Age (pp. 219231). Nordicom, University of Gothenburg.

http://urn.kb.se/resolve?urn=urn:nbn:se:norden:org:diva-12034

Blum-Ross, A., \& Livingstone, S. (2017). "Sharenting," parent blogging, and the boundaries of the digital self. Popular Communication, 15(2), 110-125.

https://doi.org/10.1080/15405702.2016.1223300

Cino, D., \& Vandini, C. D. (2020a). "Why Does a Teacher Feel the Need to Post My Kid?": Parents and Teachers Constructing Morally Acceptable Boundaries of Children's Social Media Presence. International Journal of Communication, 14(0), 20.

Cino, D., \& Vandini, C. D. (2020b). "My kid, my rule": Governing children's digital footprints as a source of dialectical tensions between mothers and daughters-in-law. Studies in Communication Sciences, 1-22-1-22. https://doi.org/10.24434/j.scoms.2020.02.003

Helmond, A. (2015). The Platformization of the Web: Making Web Data Platform Ready. Social Media + Society, 1(2), 2056305115603080. https://doi.org/10.1177/2056305115603080

Highfield, T. (2018). Emoji hashtags // hashtag emoji: Of platforms, visual affect, and discursive flexibility. First Monday. https://doi.org/10.5210/fm.v23i9.9398

Highfield, T., \& Leaver, T. (2016). Instagrammatics and digital methods: Studying visual social media, from selfies and GIFs to memes and emoji. Communication Research and Practice, 2(1), 47-62. https://doi.org/10.1080/22041451.2016.1155332 
Jorge, A., Marôpo, L., Coelho, A. M., \& Novello, L. (2021). Mummy influencers and professional sharenting. European Journal of Cultural Studies.

https://doi.org/10.1177/13675494211004593

Mäkinen, K. (2020). Resilience and vulnerability: Emotional and affective labour in mom blogging. New Media \& Society. https://doi.org/10.1177/1461444820941196

Mortensen, M., \& Jerslev, A. (2014). Taking the extra out of the extraordinary: Paparazzi photography as an online celebrity news genre. International Journal of Cultural Studies, 17(6), 619-636. https://doi.org/10.1177/1367877913503425

Ouvrein, G., \& Verswijvel, K. (2019). Sharenting: Parental adoration or public humiliation? A focus group study on adolescents' experiences with sharenting against the background of their own impression management. Children and Youth Services Review, 99, 319-327. https://doi.org/10.1016/j.childyouth.2019.02.011

Siibak, A., \& Traks, K. (2019). The dark sides of sharenting. Catalan Journal of Communication and Cultural Studies, 11(1), 115-121.

Whannel, G. (2005). Media Sport Stars: Masculinities and moralities. Routledge. 